\title{
Influence of the abrasive particles size in the micro-abrasion wear tests of TiAlSiN thin coatings
}

\author{
M.F.C. Andrade ${ }^{\text {a }}$, R.P. Martinho ${ }^{\text {, }}$,F.J.G. Silva ${ }^{\mathrm{a}, *}$, R.J.D. Alexandre ${ }^{\mathrm{c}}$, A.P.M. Baptista ${ }^{\mathrm{d}}$
}

\begin{abstract}
Ball rotating micro-abrasion tribometers are commonly used to carry out wear tests on thin hard coat-ings. In these tests, different kinds of abrasives were used, as alumina $\left(\mathrm{Al}_{2} \mathrm{O}_{3}\right)$, silicon carbide $(\mathrm{SiC})$ or diamond. In each kind of abrasive, several particle sizes can be used. Some studies were developed in order to evaluate the influence of the abrasive particle shape in the micro-abrasion process. Nevertheless, the particle size was not well correlated with the material removed amount and wear mechanisms. In this work, slurry of SiC abrasive in distilled water was used, with three different particles size. Initial sur- face topography was accessed by atomic force microscopy (AFM). Coating hardness measurements were performed with a micro-hardness tester. In order to evaluate the wear behaviour, a TiAlSiN thin hard film was used. The micro-abrasion tests were carried out with some different durations. The abrasive effect ofthe SiC particles was observed by scanning electron microscopy (SEM) both in the films (hard material) as in the substrate (soft material), after coating perforation. Wear grooves and removed material rate were compared and discussed.
\end{abstract}

Keywords: Abrasive particles, Micro-abrasion, Hard coatings, Wear

\section{Introduction}

Abrasion is the most common wear mechanism. It is estimated that $50 \%$ of wear problems in industry are due to abrasion [1]. This phenomenon conducted some researchers to develop tribological testers in order to simulate the abrasion effects observed. In these cases, the test conditions may be as close as possible to the real work conditions and the test methods can be well-characterized and reproducible [2].

In order to improve the surface wear resistance, thin hard films are usually used. However, these coatings introduce a new tribologicalbehaviourdueto theinterfacesubstrate/film. Dependingon the contact geometry, some configurations like pin-on-disk, blockon-ring, and so on, are available. In 1991, Kassman et al. referred the micro-abrasion as a new test method to evaluate the abrasion wear behaviour of thin films [3]. Nowadays, the sphere-on-flat configuration is widely employed to test micro-abrasion wear behaviour of thin hard films, using abrasive slurry which is typically constituted by a dispersion of silicon carbide, alumina or diamond particles in distilled water. In this configuration, two wear modes can occur: two or three-body abrasion [4-6]. During the ball-cratering tests, it is necessary to ensure that either two or three-body abrasion mechanisms occurs [6]. There is some evidence that more reproducible results can be obtained with three-body abrasion mechanism [6,7]. Some authors sought the best conditions in order to obtain threebody abrasion and well-defined craters in some specific substrates $[8,9]$.

It has several parameters that conditioning the dominant wear mode in the micro-scale abrasion, as the normal load, abrasive concentration in the slurry, abrasive material, sample and ball material, abrasive particle geometry and surface condition of the ball $[4,5,10-13]$. Some efforts were developed in order to formulate theoretical models to predict the wear evolution and particles motion during the test $[6,14,15]$. Other studies were carried out in order to correlate the particles geometry with the wear behaviour [16]. Some authors referred that the particle shape is the main factor that influenced the abrasivity [17]. Some investigations were already done in order to compare the wear rate obtained with different abrasive particle materials and different types of slurries $[18,19]$. Studies with large particles size in micro-abrasion wear tests were already done [20-22]. However, no comparative studies with different abrasive particle size in the same test conditions were found. 

Table 1

DIN CK45 composition evaluated by mass spectroscopy.

\begin{tabular}{lllll}
\hline C & Si & Mn & P & S \\
\hline $0.44 \%$ & $0.14 \%$ & $0.54 \%$ & $0.013 \%$ & $0.02 \%$ \\
\hline
\end{tabular}

The main objectives of this work were to study the abrasive particles size's influence in the micro-abrasion wear process and to evaluate the morphology and wear behaviour of the TiAlSiN PVD sputtered coatings. These films represent a natural evolution of the TiN and TiAlN commonly used in cutting tools and engineered componentsunder severewearconditions. Mechanical properties of the TiAlSiN coatings were already studied as monolayer or integrated in multilayered systems $[23,24]$.

\section{Experimental}

\subsection{Substrate characterization and preparation}

DIN CK45 steel was selected as substrate material because it is easy to machine, is commonly used in machine parts and present a good compromise between properties and cost. This steel was used as received (annealed). The composition was evaluated by mass spectroscopy as follows (Table 1 ).

Some mechanical properties of this steel were provided by the steel maker. The hardness was evaluated via EMCO M4U 025 Hardness Tester provided with a Brinell tungsten carbide indenter with $2.5 \mathrm{~mm}$ diameter, using a normal load of $187.5 \mathrm{kgf}$ during $5 \mathrm{~s}$ (Table2).

Samples had a quadrangular shape of $25 \mathrm{~mm} \times 25 \mathrm{~mm}$, with $2 \mathrm{~mm}$ thickness. This geometry was selected in order to turn easy the machining tasks, the morphological and mechanical characterization and the fixation on the tribometer. After cutting, the work surfaces were prepared by milling and grinding. The surface was not polished as usually used in industrial environment. Prior to the TiAlSiN film deposition, the substrate surface was characterized by atomic force microscopy (AFM). This analysis was made with VEECO MULTIMODE AFM equipment ( $7 \mathrm{~nm}$ tip radius) provided with the NanoScope 6.13 software, respectively. The surface area used for the AFM analysis was $10 \mu \mathrm{m} \times 10 \mu \mathrm{m}$. Two main parameters were analysed: average roughness $(R \mathrm{a})$ and maximum roughness height $\left(R_{\max }\right)$ according to DIN 4768.

\subsection{Samples coating process and parameters}

Prior to deposition process, the samples were cleaned in an ethanol ultrasonic bath during $20 \mathrm{~min}$. After this, the samples were mounted in the PVD reactor, in order to suffer a sputter-cleaning process in the vacuum (inverting the usual polarization). After preparation, samples were submitted to coating process. In order to obtain a TiAlSiN thin film, an industrial CemeCon CC800/9ML PVD Magnetron Sputtering equipment was used, provided with a central holder in order to fasten the samples towards the four targets involved in the deposition process. This holder was animated by a rotational motion during the coating process in order to promote a better molecular distribution and homogeneous thin layers. Parameters used in the PVD deposition were the following ones (Table3).

Table 2

DIN CK45 mechanical properties.

\begin{tabular}{lr}
\hline Tensile strenght (MPa) & 440 \\
Brinell hardness (HBW 2.5/187.5/5) & 200 \\
Poisson coefficient & 0.30 \\
\hline
\end{tabular}

Table 3

PVD sputtering deposition parameters.

\begin{tabular}{ll}
\hline Time deposition $(\mathrm{min})$ & 240 \\
Pressure $(\mathrm{mPa})$ & 500 \\
Temperature $\left({ }^{\circ} \mathrm{C}\right)$ & 450 \\
Bias $(\mathrm{V})$ & -60 \\
Target current $(\mathrm{A})$ & 20 \\
Holder rotational speed $(\mathrm{rpm})$ & 1 \\
Targets material & TiAlSi \\
\hline
\end{tabular}

\subsection{Samples surface and wear behaviour characterization}

After PVD deposition, the sample surfaces were characterized by means of the same equipments used in the substrate characterization.

Surface moderateroughness and surfaceagglomerateshinder to take accurate nano-hardness indentations in the samples used in this work. Hence, some samples substrates were polished, TiAlSiN coated in the same PVD equipment with the same parameters and submitted to six nano-hardness measurements. The obtained result for nano-hardness is $32 \pm 4 \mathrm{GPa}$.

The film adhesion was accessed by two different techniques: scratch-test and indentation. In order to evaluate the cohesive and adhesive failures, was used a scratch-tester CSM REVETEST not provided with acoustic emission. The load range selected was $0-80 \mathrm{~N}$ and the load was increase at the rate of $100 \mathrm{~N} \mathrm{~min}^{-1}$. The sliding speed selected was $10 \mathrm{~mm} \mathrm{~min}^{-1}$. The scratch was produced by a diamond Rockwell indenter. Due to the surface texture, the scratchtests were carried out in two different directions: parallel and perpendicular to the light grooves left by the grinding process. The grooves produced were carefully analysed by optical microscopy in order to understand where cohesive and adhesive failures happen. Complementary to the scratch-tests, Rockwell indentations were done with the same hardness tester used to the substrate hardness evaluation. Indentation test werecarried outwith fourdifferent loads: $98 \mathrm{~N}(10 \mathrm{kgf}), 196 \mathrm{~N}(20 \mathrm{kgf}), 294 \mathrm{~N}(30 \mathrm{kgf})$ and $980 \mathrm{~N}$ $(100 \mathrm{kgf})$. Border craters results were compared with the effects shown in the VDI 3198: 1991 standard.

In order to access to the film thickness, a sample portion was cut and subject to metallographic preparation. The thickness measurement was carried out in a cross-section view in FEI Quanta 400 FEG scanning electron microscope. The same equipment was used to characterize the surface morphology.

The wear characterization was carried out on PLINT TE-66 ballcratering equipment. The rotation speed of $80 \mathrm{rpm}(0.105 \mathrm{~m} / \mathrm{s})$ was used. The normal load of $0.25 \mathrm{~N}$ was fixed for all the tests. The test durations were 200 cycles, 500 cycles and 700 cycles (corresponding to sliding distances of $15.71 \mathrm{~m}, 39.27 \mathrm{~m}$ and $54.98 \mathrm{~m}$, respectively). For each duration and abrasive particles size, three runs were made. A polished ball of AISI 52100 steel of $25 \mathrm{~mm}$ diameter was etched in a $10 \%$ NITAL solution during $20 \mathrm{~s}$, in order to increase its superficial roughness in order to promote entrainment of the abrasive into the contact area. In order to test the coating wear behaviour under some different abrasive particles size, three differentSiC grits wereused, with the following designations: F800, F1000 and F1200, according to FEPA-Standard 42-2: 2006 $(6.5 \pm 1 \mu \mathrm{m}, 4.5 \pm 0.8 \mu \mathrm{m}$ and $3.0 \pm 0.5 \mu \mathrm{m}$, respectively). A particle size distribution analysis was made, in order to understand further wear phenomena. Table 4 shows that the size ranges establish in the norm were not accomplished by the abrasives used. Abrasive particles had the same shape and were bought at the same provider. The abrasive concentration was $35.4 \mathrm{~g} \mathrm{SiC}$ to $100 \mathrm{ml}$ of distilled water.

After wear tests, samples were cleaned in water and dried. Wear craters were observed by optical microscopy (OLYMPUS BX51 M optical microscope provided with ANALYSIS DOC software for 

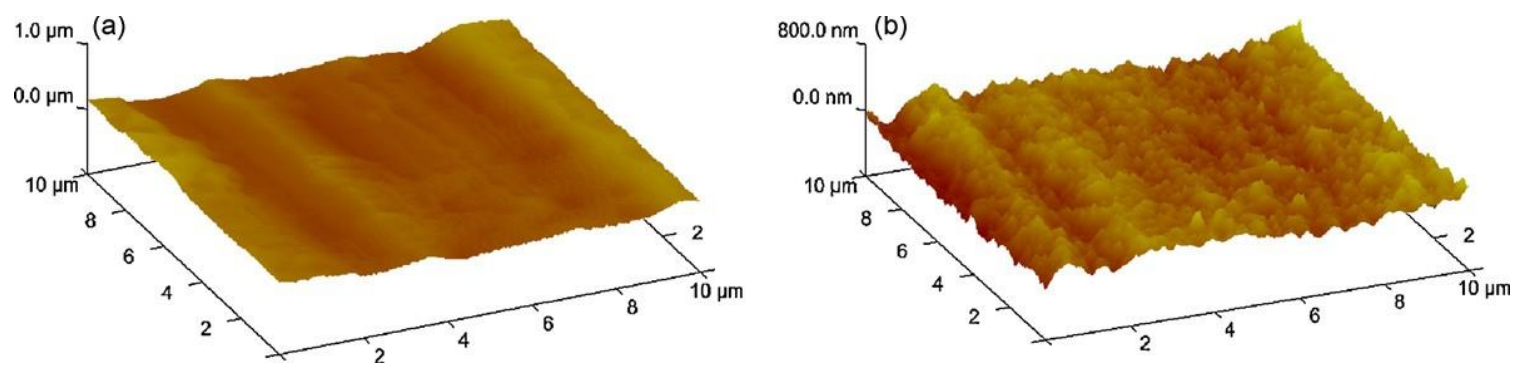

Fig. 1. AFM analysis of (a) the substrate and (b) TiAlSiN coating.
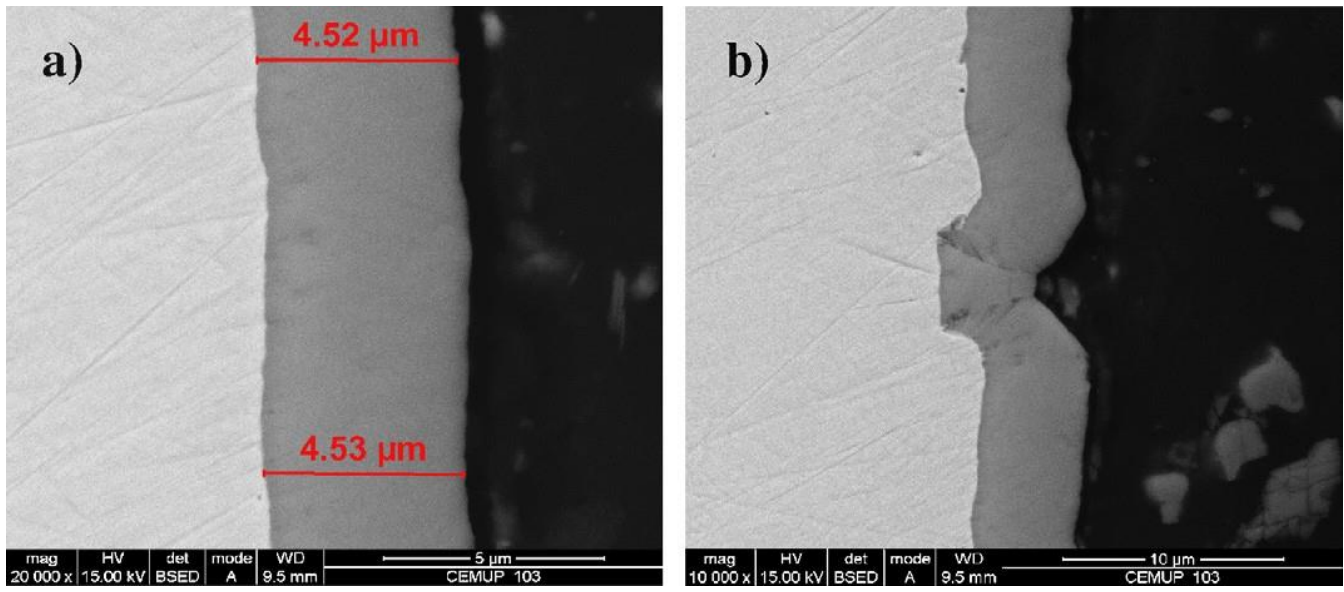

Fig. 2. (a) SEM cross-section observations of the TiAlSiN coating thickness; (b) the film follows the substrate defects when the thickness remains the same.

measurements) and scanning electron microscopy (SEM) (FEI Quanta 400 FEG scanning electron microscope).

\section{Results}

The roughness analysis of the substrate is presented in Table 5.

As can be seen in Table 6, the roughness analysis of the TiAlSiN film presents lower values than the substrate. Observing the AFM results in Fig. 1, we can conclude that the PVD process creates a small roughness proper of the physical small particles projection, but this does not hold up with the average roughness or maximum roughness height. This fact allows concluding that this set of parameters used in the PVD sputtering process promotes the

\section{Table 4}

Size distribution analysis of abrasive particles.

\begin{tabular}{lllllll}
\hline Abrasive & \multicolumn{6}{l}{ Size $(\mathrm{m})$} \\
\cline { 2 - 6 } & $<10 \%$ & $<25 \%$ & $<50 \%$ & $<75 \%$ & $<90 \%$ & Mean \\
\hline F800 & 1.646 & 3.856 & 5.818 & 7.134 & 9.116 & 5.776 \\
F1000 & 0.838 & 2.857 & 3.953 & 6.213 & 7.861 & 4.249 \\
F1200 & 0.151 & 0.348 & 2.244 & 4.294 & 5.900 & 2.573 \\
\hline
\end{tabular}

Table 5

Substrate roughness analysis.

\begin{tabular}{ll}
\hline$R_{\mathrm{a}}(\mu \mathrm{m})$ & $R_{\max }(\mu \mathrm{m})$ \\
\hline 0.128 & 2.067 \\
\hline
\end{tabular}

Table 6

TiAlSiN coating roughness analysis.

\begin{tabular}{ll}
\hline$R_{\mathrm{a}}(\mu \mathrm{m})$ & $R_{\max }(\mu \mathrm{m})$ \\
\hline 0.060 & 0.630
\end{tabular}

valleys fulfilling and do not increase the peaks, despite the small roughness induced.

The observation of the cross-section coating allows concluding that the film thickness was approximately $4.5 \mu \mathrm{m}$ and it had a good uniformity, as shown in Fig. 2. The PVD sputtering process and parameters used allows competitive films growing that accomplish the substrate defects, as can see in Fig. 2b. Another view withoutmetallographic preparation allows the observation of a columnar structure, as can be seen in Fig. 3. The surface morphology can be seen in Fig. 4a, resulting of theSEM analysis. The surface presents some defects, as can be seen in Fig. $4 b$, which can affect

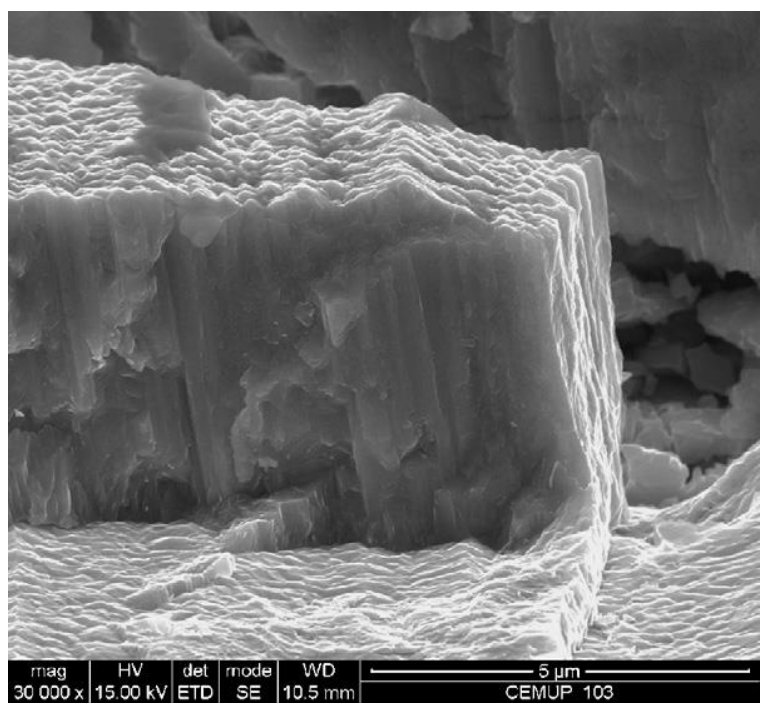

Fig. 3. SEM cross-section observations of the TiAlSiN coating after mechanical fracture, showing its columnar structure. 

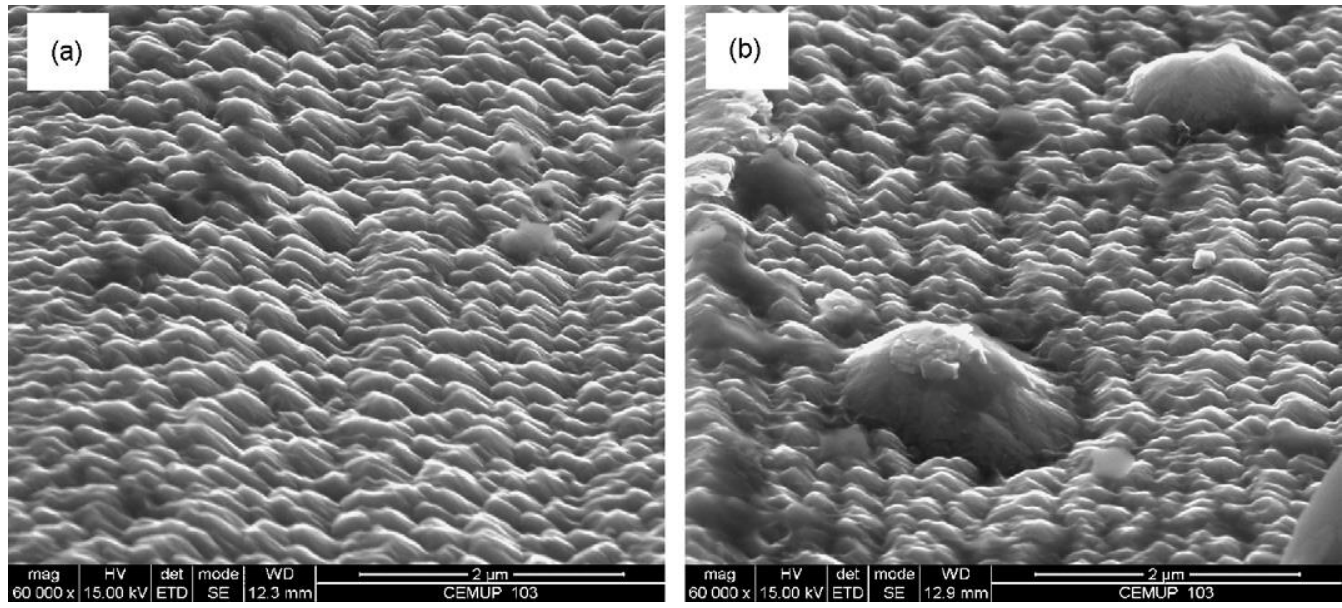

Fig. 4. (a) SEM morphological analysis of the TiAlSiN coating; (b) defects present in the film.

the wear behaviour. These aggregates results of the preferential growth around some initial sputtered particles. Due to thermodynamic preferable conditions, some particles tends to grow over it selves, resulting in high dimension aggregates like depicted in Fig. $4 \mathrm{~b}$. These heterogeneities can be the origin of different wear mechanisms involved in the wear process. This phenomenon can be worked in the PVD parameters process, in order to minimize the effect. However, other film characteristics can be harmed by the new set of parameters.

Scratch-tests were carried out in order to evaluate the adhesion between the film and the substrate. The failure mechanisms were analysed by optical microscopy, observing carefully the scratch grooves. Each failure mechanism was identified and measured the corresponding distance to the start point, in order to observe the corresponding normal load in the range of $0-80 \mathrm{~N}$. The first cohesive and adhesive failures were registered at $17 \mathrm{~N}$ and $25 \mathrm{~N}$, respectively. The results obtained in each direction were similar and were above the expectations, maybe due to the high film hardness and surface roughness. In order to complement these results, a few indentations tests were done. Some results can be seen in Fig. 5, where it is possible to observe the presence of small cracks in the indentation border. According to the VDI 3198: 1991 standard, these results can be classified as "HF1" behaviour. No border spallation was verified in the border. The indentation results can be more accurate than the scratch-tests, because the lower influence of the surface roughness, film hardness and coating thickness and because the normal load increasing is slower.

Prior to the micro-abrasion tests, the different abrasive particles used in this work were analysed by SEM. Its shape and size uniformity can be seen in Fig. 6. As can be observed in those images,

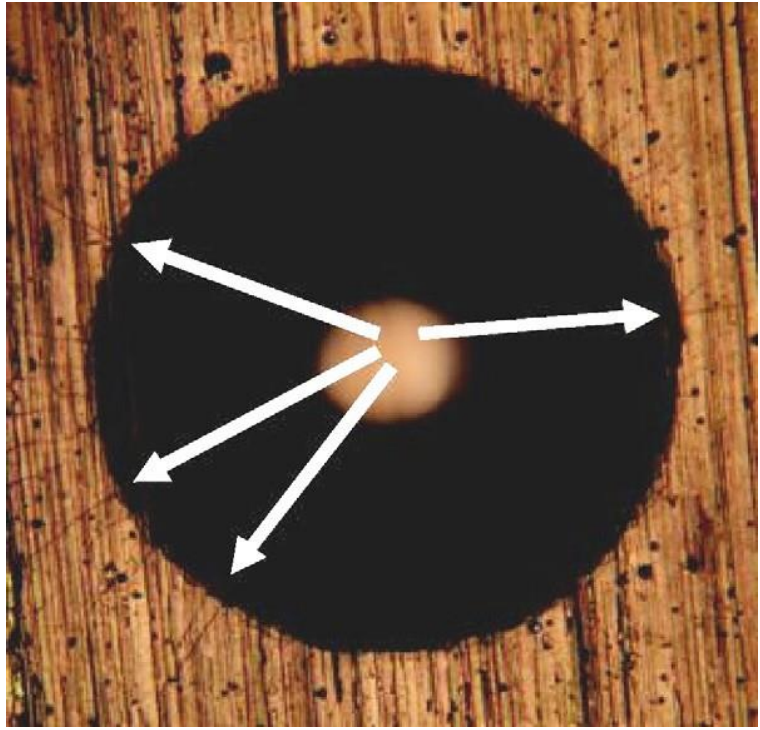

Fig. 5. Image of the cracks caused by the Rockwell indentation process at $30 \mathrm{kgf}$

the $\mathrm{SiC}$ F1200 abrasive particles present a wide range of particles size when compared with the others. In fact, the SiC F1200 abrasive shows a large number of low size particles mix with some particles with similar dimensions with the SiC F1000 particles. Despite the provider to be the same, SiC F1000 and F800 abrasive particles shows higher sizehomogeneity.
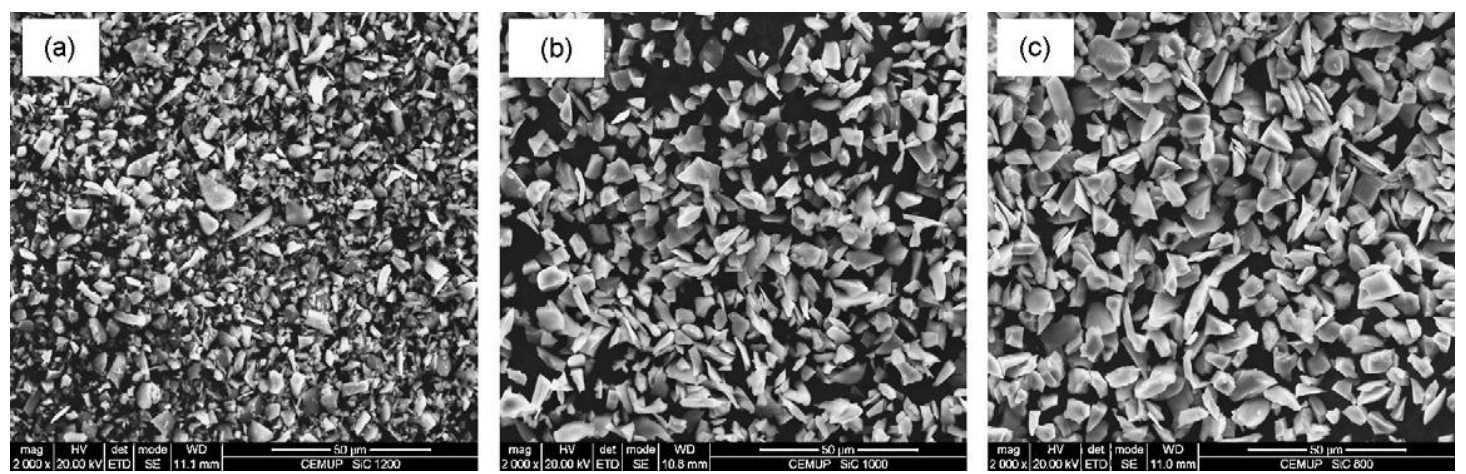

Fig. 6. (a) SiC F1200 abrasive particle; (b) SiC F1000 abrasive particles; (c) SiC F800 abrasive particles. 
Table 7

Micro-abrasion wear tests with SiC slurry: summarised results.

\begin{tabular}{|c|c|c|c|c|c|}
\hline Abrasive particles grade & Ball revolutions & Sliding distance $(\mathrm{m})$ & Normal load (N) & $\begin{array}{l}\text { Removed volume }\left(\mathrm{mm}^{3}\right) \\
\text { uncoated samples }\end{array}$ & $\begin{array}{l}\text { Removed volume }\left(\mathrm{mm}^{3}\right) \\
\text { TiAlSiN coated samples }\end{array}$ \\
\hline F1200 & 200 & 15.71 & 0.25 & 1.143 & $6.70 \mathrm{E}-03$ \\
\hline F1200 & 500 & 39.27 & 0.25 & 1.343 & $1.28 \mathrm{E}-02$ \\
\hline F1200 & 700 & 54.98 & 0.25 & 1.453 & $1.75 \mathrm{E}-02$ \\
\hline F1000 & 200 & 15.71 & 0.25 & 1.257 & $9.80 \mathrm{E}-03$ \\
\hline F1000 & 500 & 39.27 & 0.25 & 1.5 & $1.99 \mathrm{E}-02$ \\
\hline F1000 & 700 & 54.98 & 0.25 & 1.663 & $3.00 \mathrm{E}-02$ \\
\hline F800 & 200 & 15.71 & 0.25 & 1.313 & $1.17 \mathrm{E}-02$ \\
\hline F800 & 500 & 39.27 & 0.25 & 1.56 & $2.33 E-02$ \\
\hline F800 & 700 & 54.98 & 0.25 & 1.64 & $2.84 \mathrm{E}-02$ \\
\hline
\end{tabular}

The optical microscope wear craters observation allows determining the scars average diameter. All the scars presented a quasi-uniform spherical shape. The material removed volume was calculated according $[1,16,18]$ to the expression as follow:

$V \approx \frac{n b^{4}}{64 R}$

where $V$ is the removed material volume, in $\mathrm{mm}^{3}, b$ is the outer crater diameter, in $\mathrm{mm}$, and $R$ is the counter-body ball radius, in $\mathrm{mm}$. This expression is valid only for the situation $b \ll R$. The microabrasion wear results were summarized and presented on Table 7. The same results were compiled by abrasive particle size and plotted in the graphics presented in Fig. 7. In these graphics, a trend line fitting the punctual results was drawn for each abrasive particle size (both for uncoated and TiAlSiN coated samples), in order to predict the surface wear life. Table 8 presents the wear coefficients calculated based on integrated form [25] of an equation originally proposed by Kassmanetal. [3]. Attending to the thickness observed, film removed volume was calculated in order toestablish the coating wear rate taking in attention the final crater diameter corresponding to each test. Wear coefficient of the substrate was calculated taking in account the crater final diameters corresponding to the micro-abrasion tests carried out only on the uncoated samples.

Ascanbeobservedin Tables7and 8, TiAlSiN thinfilms promotea significant increase of the surface life under severe micro-abrasion conditions. This fact is more evident for low number of cycles, when the film is compact. After the film perforation, its efficiency decrease, because the better wear resistance is ensuring only by an external ring delimited by the crater. If this ring is important in the beginning, the film degradation rate increase after perforation and the visible area of the substrate in the crater tends to increase quickly. This phenomenon seems as efficient as lower is the film adhesion to the substrate. Indeed, if the film adhesion is reduced, some detachments can be occurring in the crater border, helping the film degradation. Observing Fig. 8, it is possible to conclude that the adhesion of the TiAlSiN film to substrate is very good. In fact, the crater presented in Fig. 8a shows a circle shape very regular and the micro-abrasion grooves in Fig. $8 \mathrm{~b}$ and c have some film portions between them, showing that the film detachment between grooves are not easily obtained.

Despite the presence of aggregates on TiAlSiN films, no detachment effect was felt near or on the crater borders. However, these aggregates may contribute to wear process by two ways: (a) in the initial contact process, they are the first particles to leave the film and (b) these particles, depending of their size, may affect the film surface during the way out motion.

Observing the three graphics presented in Fig. 7, it can be conclude that the abrasive particle size affects determinedly the wear results and mechanisms present in the wear process. Indeed, when the SiC F1200 abrasive slurry promotes moderate wear results, the other $\mathrm{SiC}$ abrasives presents a similar wear rate between them, but higher than SiC F1200. Also, it is possible to observe that the trend lines for SiC F800 and SiC F1000 presents a higher slope than SiC F1200 trend line. This fact allows predicting that the microabrasion wear produced by higher abrasive particle size is more intense than the lower dimension abrasive particles. However, the trend not seems linear. Indeed, the behaviour difference between SiCF1200 and SiCF1000 particles is similar. In somecases, SiCF1000 particles produce higher micro-abrasion wear than SiC F800 particles, as can be observed in the graphic present in Fig. 7b. In this case, for uncoated samples, the trend line slope presents the high-

(a) Removed Material Volume - Abrasive: SiC F800

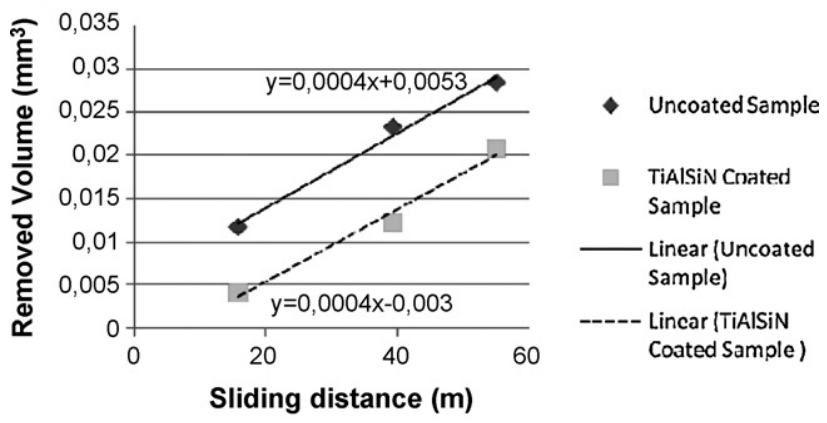

(b) Removed Material Volume - Abrasive: SiC F1000

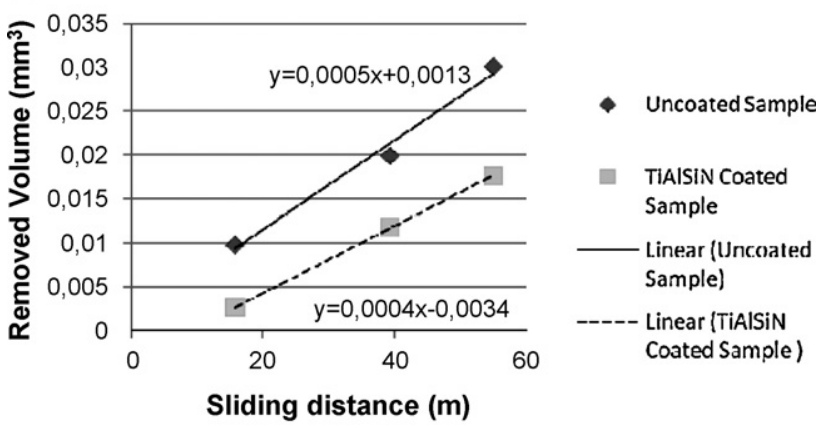

(c) Removed Material Volume - Abrasive: SiC F1200

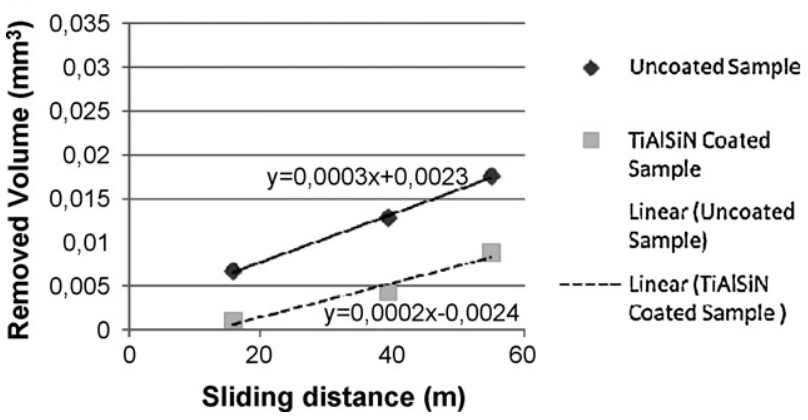

Fig. 7. Removed volume by micro-abrasion with (a) SiCF800 abrasive particles; (b) SiCF1000 abrasive particles; (c) SiCF1200 abrasive particles. 
Table 8

Wear coefficients: summarised results.

\begin{tabular}{|c|c|c|c|c|c|}
\hline Abrasive particles grade & Sliding distance $(\mathrm{m})$ & Normal load (N) & $\begin{array}{l}\text { Wear coefficient } \\
\left(\mathrm{mm}^{3} / \mathrm{N} \mathrm{m}\right) \text { substrate }\end{array}$ & $\begin{array}{l}\text { Wear coefficient }\left(\mathrm{mm}^{3} / \mathrm{N} \mathrm{m}\right) \\
\text { coating }\end{array}$ & $\begin{array}{l}\text { Wear cefficient }\left(\mathrm{mm}^{3} / \mathrm{N} \mathrm{m}\right) \\
\text { substrate + cating }\end{array}$ \\
\hline F1200 & 15.71 & 0.25 & 0.291025 & $6.36 \mathrm{E}-4$ & $1.71 \mathrm{E}-03$ \\
\hline F1200 & 39.27 & 0.25 & 0.136797 & $3.68 \mathrm{E}-4$ & $1.30 \mathrm{E}-03$ \\
\hline F1200 & 54.98 & 0.25 & 0.105711 & $3.14 \mathrm{E}-4$ & $1.27 \mathrm{E}-03$ \\
\hline F1000 & 15.71 & 0.25 & 0.320051 & $8.09 \mathrm{E}-4$ & $2.50 \mathrm{E}-03$ \\
\hline F1000 & 39.27 & 0.25 & 0.152788 & $4.73 \mathrm{E}-4$ & $2.02 \mathrm{E}-03$ \\
\hline F1000 & 54.98 & 0.25 & 0.120989 & $3.74 \mathrm{E}-4$ & $2.19 \mathrm{E}-03$ \\
\hline F800 & 15.71 & 0.25 & 0.334309 & $9.07 \mathrm{E}-4$ & $2.97 \mathrm{E}-03$ \\
\hline F800 & 39.27 & 0.25 & 0.158900 & $4.79 \mathrm{E}-4$ & $2.37 \mathrm{E}-03$ \\
\hline F800 & 54.98 & 0.25 & 0.119316 & $3.90 \mathrm{E}-4$ & $2.07 \mathrm{E}-03$ \\
\hline
\end{tabular}

est value registered in this work. These facts can be indicate that the size of the SiC F1000 and F1200 abrasive particles is a hinge point and particles with higher dimension tend primordially to go round the contact area.

Fig. 8 shows a generic crater shape and three different detailed views of the side of the crater when the abrasive particles left the contact. Observing the images $(\mathrm{a}-\mathrm{c})$, corresponding to the same wear test parameters but with different abrasive particle size used, it is possible to observe that exists three micro-abrasion groove steps, corresponding to each abrasive particle size used. It was verified that the groovestep is higherforSiCF800 abrasive particles, and lower for the SiC F1200. This phenomenon can be due to the initial particles distribution in the contact inlet area. Indeed, the first particles that starts the micro-abrasion, draws the first grooves with an enough distance between them in order to sliding and rolling dur- ing the contact. Some of them can be captured by the ball surface, producing after this two-body abrasion.

Attending to observe the images (b-d), it is possible to observe that the wear mechanisms involved in the micro-abrasion with $\mathrm{SiC}$ F800, F100 and F1200 are also different. In fact, large size particles like SiC F800 seem to produce a well-defined border where the abrasive particles left the contact. With these particles it is possible to observe that the wear grooves are ill-defined, suggesting that a three-body wear mechanism was present. In this process, large size abrasive particles did not draw a linear trajectory across the contact area, reducing the evidence of grooves. On the other hand, craters provoked by wear tests carried out with SiC F1000 or F1200 show well-defined grooves, inducing to think that a twobody micro-abrasion wear mechanism is the predominant process. This process seems to allow a better abrasive particles trajectory.
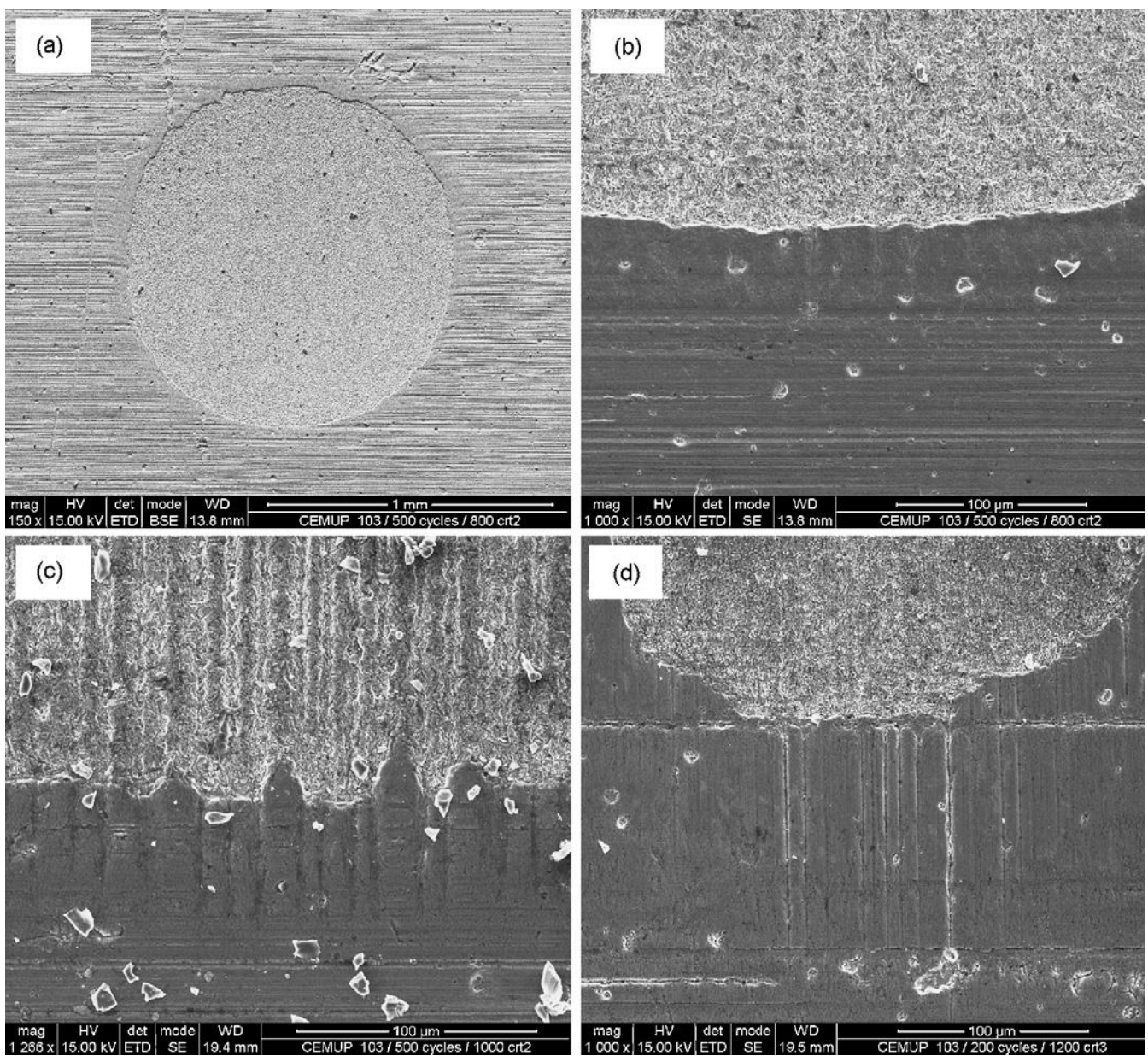

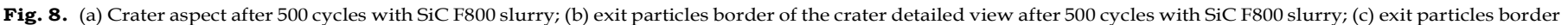
of the crater detailed view after 500 cycles with SiC F1000 slurry; (d) exit particles border of the crater detailed view after 500 cycles with SiC F1200 slurry. 
In this case, some abrasive particles could be embedded in the ball surface, producing parallel grooves in the sample surface. This fact corroborates the idea that SiC F1000 represents a particle size that can be inflecting the wear behaviour in the micro-abrasion of the thin films tribological systems.

These micro-abrasion results allows to observe that (i) small size particles enter more easily in the contact area and the way drawn is more lineal (ii) the load is carried by a large number of particles when these are smaller, decreasing the load carried per particle (iii) large size particles tend to outline the central point of contact, also hindering the entrainment of the particles into the contact (iv) a smaller number of big particles provokes a larger need of these they leave the contactoriginating a random pathway of the particles mainly near the crater exit border and (v) the F800 abrasive present a large interference among particles across the contact hindering a lineal pathway of the same ones.

\section{Conclusions}

After concluding this work, the following conclusions can be drawn:

- TiAlSiN films obtained by PVD magnetron sputtering show a very good adhesion to the steel substrate. The results were confirmed by indentation and wear grooves shape.

- The wear behaviour of these films is good, but not as good as expected. However, the wear resistance was increased substantially.

- SiCF800 abrasive slurry shows to drive to three-body wear mechanisms, with ill-defined surface grooves. In this case, the abrasive particles pathway is more irregular due to its large size.

- SiC F1000 and F1200 abrasive slurries show a different behaviour, with perfectly defined surface grooves, suggesting a two-body micro-abrasion wear mechanism.

- It is clear that larger particles as F800 has a different behaviour across the contact: the particles entrance is more difficult, a smaller number of particles carry the normal load (higher load per particle) and the particles tend to leave the contact more easily and with a random pathway.

- The smaller particles tend to present a lineal pathway with more particlescarrying the normal load and with a morelineal pathway that originates the well-defined grooves referred above.

\section{Acknowledgments}

The authors would like to thanks to INEGI - Instituto de Engenharia Mecânica e Gestão Industrial (FEUP) and CIDEM-Centro de Investigação e Desenvolvimento em Engenharia Mecânica (ISEP) by the financial support and facilities. The authors also wish to thank to Professor Teresa Vieira and Professor José Manuel Castanho of the FCTUC for scratch-tests facilities availability and useful discussion.

\section{References}

[1] T.S. Eyre, Wear characteristics of metals, Tribology International 10 (1976) 203-212.

[2] I.M. Hutchings, Erosive and abrasive wear tests for thin coatings: a unified approach, Tribology International 31 (1-3) (1998) 5-15.

[3] A. Kassman, S. Jacobson, L. Erickson, P. Hedenqvist, M. Olsson, A new test method for the intrinsic abrasion resistance of thin coatings, Surface and Coatings Technology 50 (1991) 75-84.

[4] R.I. Trezona, D.N. Allsopp, I.M. Hutchings, Transitions between two-body and three-body abrasive wear: influence of test conditions in the micro-scale abrasive wear test, Wear 225-229 (1999) 205-214.

[5] D.N. Allsopp, R.I. Trezona, I.M. Hutchings, The effects of ball surface condition in the micro-scale abrasive wear test, Tribolology Letters 5 (1998) 259264

[6] K. Adachi, I.M. Hutchings, Wear-mode mapping for the micro-scale abrasion test, Wear 205 (2003) 23-29.

[7] E. Rabinowicz, L.A. Dunn,P.G.Russell, A study of abrasivewearunder three-body conditions, Wear 4 (1961) 345-355.

[8] K. Bose, R.J.K. Wood, Influence of load and speed on rolling micro-abrasion of CVD diamond and other hard coatings, Diamond and Related Materials 12 (2003) 753-756.

[9] K. Bose, R.J.K. Wood, Optimum tests conditions for attaining uniform rolling abrasion in ball cratering tests on hard coatings, Wear 258 (2005) 322332.

[10] R.I. Trezona, I.M. Hutchings, Three-body abrasive wear testing of soft materials, Wear 233-235 (1999) 209-221.

[11] K. Adachi, I.M. Hutchings, Sensitivity of wear rates in the micro-scale abrasion test to test conditions and material hardness, Wear 258 (2005) 318-321.

[12] P.H. Shipway, The role of test conditions on the microabrasive wear behaviour of soda-lime glass, Wear 233-235 (1999) 191-199.

[13] P.H. Shipway, J.J. Hogg, Wear of bulk ceramics in micro-scale abrasion - the role of abrasive shape and hardness and its relevance to testing of ceramic coatings, Wear 263 (2007) 887-895.

[14] A. Ramalho, A geometrical model to predict the wear evolution of coated surfaces, Wear 264 (2008) 775-780.

[15] A. Ramalho, Micro-scale abrasive wear of coated surfaces-prediction models, Surface and Coatings Technology 197 (2005) 358-366.

[16] G.W.Stachowiak, Particle angularity and its relationship to abrasive and erosive wear, Wear 241 (2000) 214-219.

[17] D.A. Kelly, I.M. Hutchings, A new method for measurement of particle abrasivity, Wear 250 (2001) 76-80.

[18] P.H. Shipway, J.J. Hogg, Dependence of micro-scale abrasion mechanisms of WC-Co hardmetals on abrasive type, Wear 259 (2005) 44-51.

[19] K.I. Schiffmann, T.R. Bethke, N. Kristen, Analysis of perforating and nonperforating micro-scale abrasion tests on coated substrates, Surface and Coatings Technology 200 (2005) 2348-2357.

[20] G.B. Stachowiak, G.W. Stachowiak, J.M. Brandt, Ball-cratering abrasion tests with large abrasive particles, Tribology International 39 (1) (2006) 111.

[21] G.B. Stachowiak, G.W. Stachowiak, Wear mechanisms in ball-cratering tests with large abrasive particles, Wear 256 (2004) 600-607.

[22] G.B. Stachowiak, G.W. Stachowiak, The effects of particle characteristics on three-body abrasive wear, Wear 249 (2001) 201-207.

[23] L.A. Dobrzanski, D. Pakuła, E. Hajduczek, Structure and properties of the multi-component TiAlSiN coatings obtained in the PVD process in the nitride tool ceramics, Journal of Materials Processing Technology 157-158 (2004) 331-340.

[24] O. Nakonechna, T. Cselle, M. Morstein, A. Karimia, On the behaviour of indentation fracture in TiAlSiN hard thin films, Thin Solid Films 447-448 (2004) 406-412.

[25] Y. Kusano, K. Van Acker, I.M. Hutchings, Methods of data analysis for the microscale abrasion test on coated substrates, Surface and Coatings Technology 183 (2004) 312-327 